\title{
Erratum to: Sustained Benefit at 2 Years for Covered Stents Versus Bare-Metal Stents in Long SFA Lesions: The VIASTAR Trial
}

\author{
Johannes Lammer - Thomas Zeller - Klaus A. Hausegger • Philipp J. Schaefer • \\ Manfred Gschwendtner • Stefan Mueller-Huelsbeck • Thomas Rand • \\ Martin Funovics · Florian Wolf • Aljoscha Rastan · Michael Gschwandtner • \\ Stefan Puchner • Ulrich Beschorner • Robin Ristl • Maria Schoder
}

Published online: 17 March 2015

(C) Springer Science+Business Media New York and the Cardiovascular and Interventional Radiological Society of Europe (CIRSE) 2015

Erratum to: Cardiovasc Intervent Radiol (2015)

35:25-32

DOI 10.1007/s00270-014-1024-9

In the published article Fig. $3 \mathrm{~A}$ and $\mathrm{B}$ are a duplicate of Figs. 1B and 2. The correct artworks of Fig. 3A and B appear below.
The online version of the original article can be found under doi:10.1007/s00270-014-1024-9.

J. Lammer $(\bowtie) \cdot$ M. Funovics · F. Wolf · S. Puchner .

M. Schoder

The Department of Cardiovascular and Interventional

Radiology, Department of Biomedical Imaging and Image-

guided Therapy, Medical University Vienna, Waehringer

Guertel 18-20, 1090 Vienna, Austria

e-mail: jlammer@gmx.at; johannes.lammer@meduniwien.ac.at

M. Funovics

e-mail: martin.funovics@meduniwien.ac.at

F. Wolf

e-mail: florian.wolf@meduniwien.ac.at

S. Puchner

e-mail: stefan.puchner@meduniwien.ac.at

M. Schoder

e-mail: maria.schoder@meduniwien.ac.at

T. Zeller · A. Rastan · U. Beschorner

Department of Angiology, Universitaets-Herzzentrum

Freiburg-Bad Krozingen, Bad Krozingen, Germany

e-mail: thomas.zeller@universitaets-herzzentrum.de

\author{
A. Rastan \\ e-mail: aljoscha.rastan@universitaets-herzzentrum.de \\ U. Beschorner \\ e-mail: ulrich.beschorner@universitaets-herzzentrum.de \\ K. A. Hausegger \\ The Department of Diagnostic and Interventional Radiology, \\ Klinikum Klagenfurt, Klagenfurt, Austria \\ e-mail: klaus.hausegger@lkh-klu.at

\section{P. J. Schaefer} \\ The Department of Radiology, University Clinics \\ Schleswig-Holstein, Kiel, Germany \\ e-mail: jp.schaefer@rad.uni-kiel.de \\ M. Gschwendtner \\ The Department of Diagnostic and Interventional Radiology, \\ Elisabethinen Hospital, Linz, Austria \\ e-mail: manfred.gschwendtner@elisabethinen.or.at
}



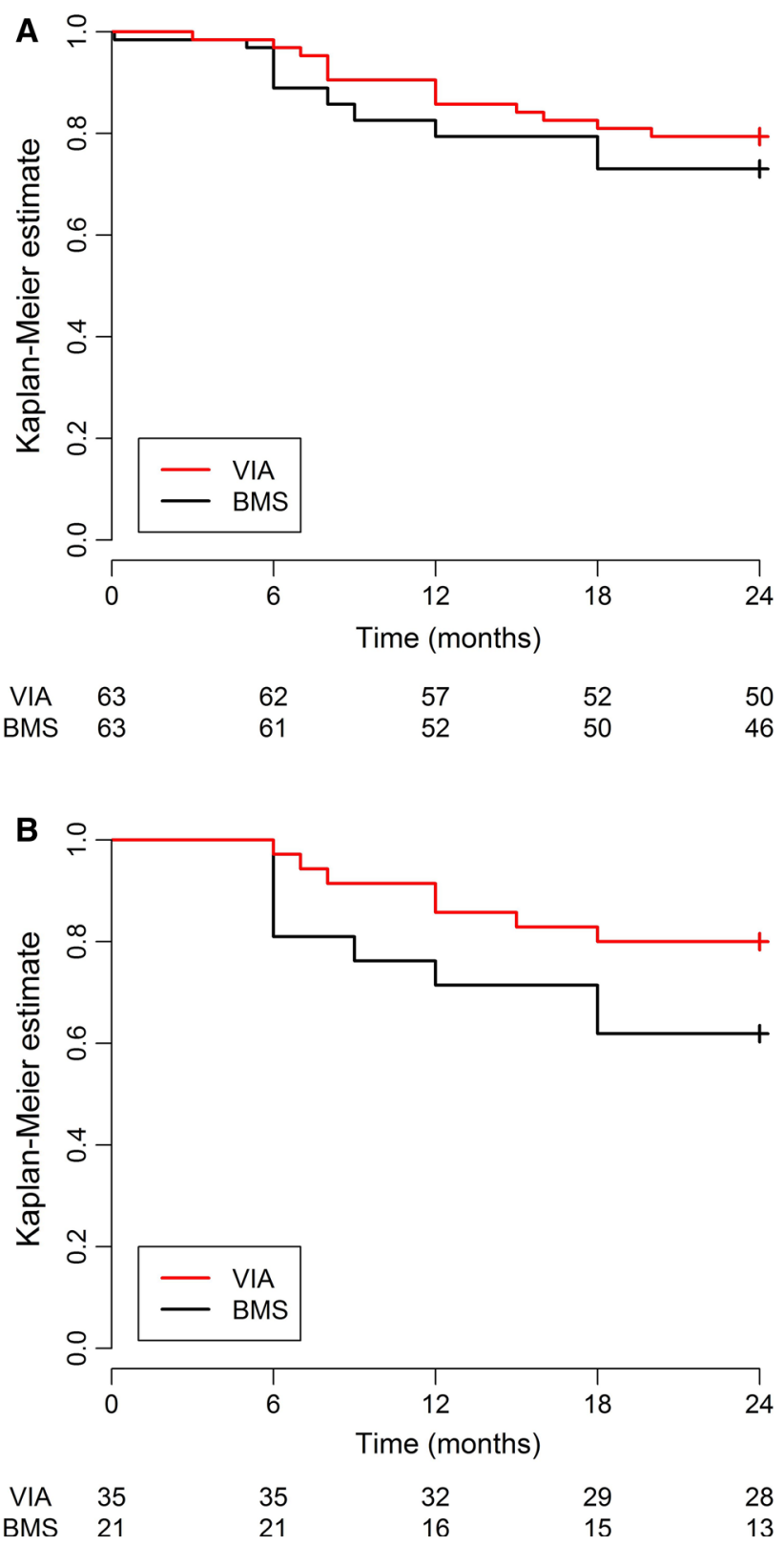

Fig. 3 Freedom of reintervention (TLR and bypass surgery) of VIA (red) versus BMS (black) in SFA lesions of patients with symptomatic PAD at 24 months (TPP): A all patients: VIA 79.4 (95\% CI 0.70-0.90) versus BMS $73.0 \%$ (95\% CI 0.63-0.85) ( $\log$ rank $p=0.37)$ for VIABAHN $^{\circledR}$ versus BMS, B in lesions $\geq 20 \mathrm{~cm}$ : VIA $80.0(95 \% \mathrm{CI}$ $0.68-0.94)$ versus BMS $61.9 \%$ (95\% CI 0.44-0.87) $(\log \operatorname{rank} p=0.13)$ for VIABAHN ${ }^{\circledR}$ versus BMS. Abbreviations as in Figs. 1 and 2. The numbers below are the patients at risk at $0,6,12,18$, and 24 months

S. Mueller-Huelsbeck

The Department of Diagnostic and Interventional Radiology,

Diakonissen Hospital, Flensburg, Germany

e-mail: muehue@diako.de

M. Gschwandtner

The Department of Angiology, Medical University Vienna,

Vienna, Austria

e-mail: michael.gschwandtner@meduniwien.ac.at

T. Rand

The Department of Radiology, Hietzing Hospital, Vienna, Austria

e-mail: thomas.rand@wienkav.at

R. Ristl

The Center for Medical Statistics, Informatics and Intelligent Systems, Medical University Vienna, Vienna, Austria e-mail: robin.ristl@meduniwien.ac.at 